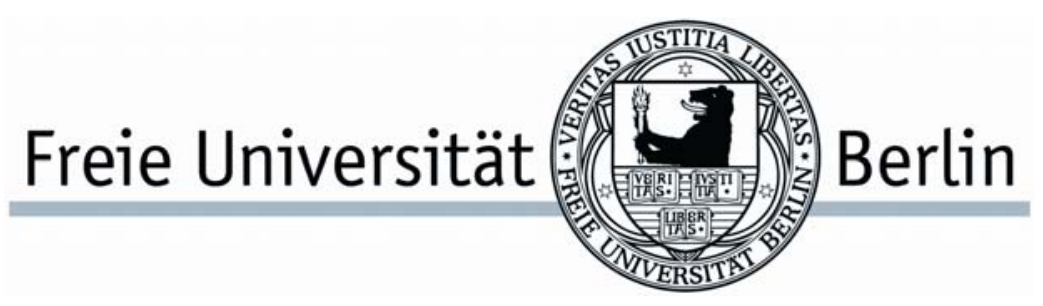

Diskussionsbeiträge des Fachbereichs Wirtschaftswissenschaft der Freien Universität Berlin

Volkswirtschaftliche Reihe

$2006 / 21$

\title{
Charity and Redistributive Taxation in a Unionized Economy
}

Giacomo Corneo

3-938369-46-9 


\title{
Charity and Redistributive Taxation in a Unionized Economy
}

\author{
Giacomo Corneo* \\ Free University of Berlin, CEPR, CESifo, IZA \\ November 2006
}

\begin{abstract}
European economies are characterized by unionized labor markets and a pronounced governmental redistribution of income. This paper studies a model where those two features are combined with the possibility for individuals to make charitable contributions to the poor. The model exhibits equilibrium unemployment that increases with the degree of altruism. It is shown that a more progressive income tax can both reduce the unemployment rate and improve the public budget. These results are driven by charity increasing wage pressure and the altruistic rich failing to internalize the effect of their donations on the wage setting behavior of the unions.
\end{abstract}

Keywords: Equilibrium Unemployment, Income Tax, Charity, Trade Unions.

JEL-Classification: J50, H24.

*Address: Department of Economics, Free University of Berlin, Boltzmannstr. 20, 14195 Berlin, Germany; e-mail: gcorneo@wiwiss.fu-berlin.de. 


\section{Introduction}

Despite its generous safety nets, Europe has not eradicated income poverty. Quite to the contrary, relative poverty is currently on the rise in some european countries. According to recent studies, poverty rates of $10 \%$ and more are common in Europe. ${ }^{1}$ In the last few years, even absolute poverty has increased in some countries. ${ }^{2}$ High and persistent unemployment is generally thought to be the main culprit of this development, and indeed the unemployed, with relative poverty rates of about 50 percent, constitute a distinctly vulnerable group.

In some countries, along with poverty, top incomes have substantially risen, so as to produce a high level of income concentration. For instance, in the case of Germany, empirical analyses based on income tax statistics data at the individual level have revealed that the top fractiles of the income distribution significantly increased their share of total income in the second half of the $1990 \mathrm{~s} .{ }^{3}$ In contrast to the bulk of the population, those top income groups mainly rely on income from business and capital. ${ }^{4}$

Increasing poverty rates and income concentration might bring about a novel environment for some european labor markets. Continental western Europe is still characterized by powerful trade unions and progressive tax-transfer systems. However, those institutions cannot prevent income disparities from growing. If income disparities become large, a situation may arise where the unemployed poor come to rely for their subsistance not only upon benefits and social assistance but also upon support from private organizations, i.e. charity. ${ }^{5}$ This environment may entail distinct implications for how the labor market

\footnotetext{
${ }^{1}$ Poverty line defined at 60 percent of median disposable income adjusted for family size. See e.g. Hauser and Nolan (1999) and Sainsbury and Morissens (2002) for cross-country comparisons. For Germany, Frick et al. (2005) report results for the period 1985-2003; poverty increased over the last five years and reached a maximim of $15.3 \%$ in 2003.

${ }^{2}$ In the case of Germany, Becker and Hauser (2004) document a rise of absolute poverty rates between 2000 and 2002, followed by a moderate decline in 2003.

${ }^{3}$ See Bach et al. (2005) for the period 1992-1998. Preliminary results obtained from more recent data suggest that income concentration further increased in the years after 1998. For evidence on the long-run evolution of income concentration in several countries, see Atkinson and Piketty (2006).

${ }^{4}$ See e.g. Bach et al. (2005, Table 4).

${ }^{5}$ The current situation in the US offers some hints as to how support for the unemployed in some
} 
works. Exploring those implications is the aim of the current paper.

I develop a simple model where unionized labor markets and governmental redistribution are combined with the assumption that some individuals have an operative altruistic motive. Altruism is modelled as in Arrow's (1981) celebrated essay, where it is derived from reasonable axioms on individual preferences over income distributions. In the model, individuals can use their post-fisc income to make charitable contributions to support the poor. The trade unions are endowed with wage setting power, and correctly anticipate how market incomes are redistributed by both the government and voluntary contributions to the poor.

The model exhibits equilibrium unemployment that increases with the degree of altruism. Its main result has that a more progressive income tax reduces the unemployment rate. And it is always possible to design a progressive tax reform such that the public budget is improved.

In the setting considered in this paper, the results mentioned above are robust and have a natural explanation. They are driven by the fact that individuals fail to internalize the effet of their donations on the wage setting behavior of the unions. Charitable contributions improve the standard of living of the poor and thus reduce the utility loss caused by losing a job. Therefore, donations turn out to increase wage pressure by the unions, and equilibrium unemployment is higher. Since the marginal utility of consumption is lower for the rich, the rich are those who donate. A more progressive income tax, by hitting the top incomes, reduces the average propensity to give to charities. Thereby, it reduces wage pressure and leads to a higher employment level.

Although it is rather straightforward, this link between income taxation and unemployment has not been explored so far, possibly because the joint rise of poverty and income concentration is a quite novel experience in Europe. ${ }^{6}$ The literature on trade european countries might evolve in the future. According to the AAFRC Trust for Philanthropy, in the US total yearly donations to human services amount to about 20 billions USD. This amount is close to the yearly expenditure for governmental food stamp programs.

${ }^{6}$ See e.g. the very comprehensive volume by Agell and Sorensen (2006) on tax policies and labor 
union behavior has pointed out a different mechanism through which tax progression affects equilibrium unemployment. As noted e.g. by Lockwood and Manning (1993), Corneo (1994) and Koskela and Vilmunen (1996), if wage income is subject to a progressive income tax, making the latter more progressive implies that, for a wage-negotiating union, the price of a higher take-home wage increases in terms of foregone employment. Then, the unions' demand for higher wages will decrease and employment will increase. The link put forward in the current paper provides a complementary reason as to why tax progression may have favorable employment effects in economies with unionized labor markets.

\section{The model}

The model economy is populated by $W+K$ individuals, indexed by $i=1, \ldots W+K$. The population consists of $W$ workers and $K$ capitalists. Each worker is only endowed with labor and inelastically supplies one unit of it to the firm sector. Capitalists are only endowed with entitlements in the firms' profits. There are $F$ firms, indexed by $f=1, \ldots F$ that produce a homogeneous consumption good according to $Q_{f}=A L_{f}^{\alpha}$, where $L_{f}$ is employment in firm $f, \alpha \in(0,1)$, and $A>0$. Each capitalist receives $1 / K$ of the profit of every firm.

Each firm faces a pool of workers, from which the firm can hire. Each pool contains $W / F$ workers and is represented in wage negotiations by a trade union. Without significant loss of generality, the union has the entire bargaining power. It sets the wage so as to maximize the expected utility of the workers in the pool. The firm then chooses the employment level so as to maximize its profit.

Individuals have common preferences about their own and their fellow human beings' level of consumption. Preferences are supposed to satisfy Arrow's (1981) axioms; there-

markets. 
fore, they can be represented by the following von Neumann-Morgenstern utility function:

$$
U_{i}=u\left(c_{i}\right)+\sum_{j \neq i} v\left(c_{j}\right) .
$$

The variable $c_{i}$ denotes individual $i$ 's consumption. The functions $u$ and $v$ are strictly increasing and concave and satisfy $u^{\prime}(c)>v^{\prime}(c), \forall c$. This notably implies that individuals are altruistic; however, starting from an equal distribution between individual $i$ and some other individual, $i$ would prefer to shift some income to himself. In what follows, it will be assumed that $u(c)=\epsilon \log (c)$ and $v(c)=\log (c)$, where $\epsilon>1$ can be interpreted as the degree of selfishness. Altruism asymptotically vanishes when $\epsilon$ goes to infinity.

Market income is redistributed by means of a tax-transfer system. The unemployed receive a welfare payment $z$ that is financed by income taxes paid by the employees and the capitalists; $z$ is posited to be smaller than the net wage. The income tax schedule is $T(y)=t_{1} y$ for incomes between 0 and some threshold $\bar{y}$, and $T(y)=t_{1} \bar{y}+t_{2}(y-\bar{y})$ for incomes larger than $\bar{y}$, where the marginal tax rates $t_{1}$ and $t_{2}$ are between zero and one; the income tax is progressive if and only if $t_{2}>t_{1}$.

The sequence of events is as follows. At date $t=0$ the government announces $\left(z, t_{1}, t_{2}\right)$. At date $t=1$, all trade unions set their wage level. At date $t=2$ the firms choose their employment levels; redundancies are randomly distributed across the workforce inside each pool and production occurs. At date $t=3$ each individual is permitted to give any amount of his income away to any other individual. At date $t=4$ individuals consume their post-fisc, post-charity income.

\section{Determination of equilibrium}

The model is analyzed by backward induction, i.e. agents hold rational expectations.

\subsection{Charity game}

Let $x_{i}$ denote the post-fisc income of individual $i$. This income can be used for consumption or gifts to other individuals. The amount given by an individual $i$ to an individual $j$ 
is denoted by $g_{i j} \geq 0$. Individual consumption, after all gifts have been given and received is

$$
c_{i}=x_{i}+\sum_{k \neq i} g_{k i}-\sum_{j \neq i} g_{i j} .
$$

Each individual $i$ chooses $g_{i j}$ for all $j \neq i$ so as to maximize his utility function (1), taking as given the gifts made by all other individuals, which determine all consumption levels according to $(2)$.

As shown by the above equations, the individuals' decision problems are interdependent. Taking the non-negativity of gifts into account, a Nash equilibrium of the charity game has $-u^{\prime}\left(c_{i}\right)+v^{\prime}\left(c_{j}\right) \leq 0$ and $u^{\prime}\left(c_{i}\right)=v^{\prime}\left(c_{j}\right)$ if $g_{i j}>0$ for all $i$ and $j$.

The charity game was first studied by Arrow (1981) and all his results carry over to the current model. Specifically, there is a unique allocation of consumption that is supported as a Nash equilibrium. In that equilibrium, the set of givers, defined as $\left\{i \mid g_{i j}>0\right.$ for some $\left.j\right\}$, and the set of receivers, defined as $\left\{i \mid g_{j i}>0\right.$ for some $\left.j\right\}$, are disjoint. Moreover, all receivers consume the same amount, which is the minimum consumption level in the population, and the consumption level of any giver is strictly larger than the minimum.

Of course, depending on parameter values, the set of givers and the set of receivers may be empty. In such a trivial equilibrium, post-fisc income and consumption coincide. I consider the case in which the equilibrium is nontrivial.

Since individuals have identical preferences, the set of givers includes all individuals with the highest post-fisc income and the set of receivers includes all individuals with the lowest post-fisc income. Let $x^{K}$ and $x^{L}$ respectively denote the post-fisc income of capitalists and employees. Hereafter, I assume that the parameters are such that the equilibrium level of pre-fisc income of the capitalists is strictly larger than $\bar{y}$, which is in turn strictly larger than the pre-fisc income of employees. Then, one has $x^{K}>x^{L}>$ $z$ and in a nontrivial equilibrium capitalists privately support the unemployed. As a 
consequence,

$$
u^{\prime}\left(c^{K}\right)=v^{\prime}\left(c^{U}\right),
$$

where $c^{K}$ is the consumption level of a capitalist and $c^{U}$ is consumption of an unemployed. Furthermore, I assume that the parameters are such that the employees are neither givers nor receivers. ${ }^{7}$

By (3) and the assumption that $u$ and $v$ are logarithmic one has

Proposition 1 In equilibrium, the ratio between the highest and the lowest consumption level in the population is equal to $\epsilon$ :

$$
\frac{c^{K}}{c^{U}}=\epsilon
$$

Thus, the degree of selfishness determines the consumption of the capitalists relative to the consumption of the unemployed. Let $g>0$ denote the amount that every unemployed receives on average from a capitalist. Then,

$$
c^{U}=z+K g
$$

and

$$
c^{K}=x^{K}-U g
$$

where $U$ is the total number of unemployed in the economy. By (4), (5) and (6), the total charity received by an unemployed is

$$
K g=K \frac{x^{K}-\epsilon z}{\epsilon K+U}
$$

The received charity is increasing with $x^{K}$ and $K$, and it is decreasing with $\epsilon, z$ and $U$.

\footnotetext{
${ }^{7}$ Otherwise, the model would generate predictions that are not in line with observation. If the employees received charity, in equilibrium they would obtain the same consumption level as the unemployed. If the employees made charitable contributions to the poor, they would have the same consumption level as the capitalists.
} 


\subsection{Unionized labor markets}

Given the wage level $w_{f}$, firm $f$ chooses its employment level $L_{f} \in[0, W / F]$ so as to maximize its profit, given by

$$
\Pi_{f}=A L_{f}^{\alpha}-w_{f} L_{f}
$$

Assuming that the solution to this maximization problem is interior, the resulting labor demand function is

$$
L_{f}=\left(\frac{\alpha A}{w_{f}}\right)^{\frac{1}{1-\alpha}} .
$$

This relationship is correctly anticipated by the trade union, that sets the wage so as to maximize the expected utility of the workers in the local pool. Each local union is posited to be small, i.e. it takes the behavior of all other unions and hence the income distribution in the rest of the economy as given.

A worker in pool $f$ is employed with probability $L_{f} F / W$ and is unemployed with the complementary probability. If employed, he achieves utility

$$
\epsilon \log \left[\left(1-t_{1}\right) w_{f}\right]+\left(L_{f}-1\right) \log \left[\left(1-t_{1}\right) w_{f}\right]+\left(\frac{W}{F}-L_{f}\right) \log \left(c^{U}\right)+\Phi
$$

where the first term is utility from own consumption and the remaining terms capture altruism: the second one is determined by the consumption level of employees in the firm, the third one by consumption of the unemployed in the firm's pool, and third one by consumption of everybody else. ${ }^{8}$

An unemployed worker obtains utility

$$
\epsilon \log \left(c^{U}\right)+L_{f} \log \left[\left(1-t_{1}\right) w_{f}\right]+\left(\frac{W}{F}-L_{f}-1\right) \log \left(c^{U}\right)+\Phi
$$

\footnotetext{
${ }^{8}$ That is,

$$
\Phi=\sum \log c_{j},
$$

where the sum is over all capitalists and all workers who do not belong to the pool of firm $f$.
} 
Computing the expected utility, after eliminating constant terms and multiplicative coefficients, one finds that the union's maximization problem boils down to

$$
\max _{w_{f}} L_{f}\left\{\log \left[\left(1-t_{1}\right) w_{f}\right]-\log \left(c^{U}\right)\right\},
$$

subject to (9). Interestingly, the degree of altruism has no direct impact on the wage demanded by the trade union. It only matters indirectly by its effect on the expected consumption level of the unemployed. This implies that workers would still agree on the same wage policy even if they had heterogeneous preferences towards others' consumption.

Proposition 2 In every firm the union sets the following wage:

$$
w=\frac{e^{1-\alpha}}{1-t_{1}} c^{U} .
$$

Proof: The FOC of the union's maximization problem reads

$$
w_{f}^{\frac{2-\alpha}{\alpha-1}}\left\{1+\log \left[\frac{\left(1-t_{1}\right) w_{f}}{c^{U}}\right]\right\}=0,
$$

which implies (10). Straightforward computations show that the SOC is satisfied. QED

\subsection{General equilibrium}

In the general equilibrium, the consumption level of the unemployed is endogenously determined. From (5) and (7) one has

$$
c^{U}=z+K \frac{x^{K}-\epsilon z}{\epsilon K+U},
$$

which shows that the consumption level of the unemployed linearly increases with the post-fisc income of the capitalist. In turn, that income level is determined by the tax schedule according to

$$
x^{K}=\left(1-t_{2}\right) y^{K}+\left(t_{2}-t_{1}\right) \bar{y},
$$


where $y^{K}$ is the pre-fisc income of capitalists. Hence, the consumption level of the unemployed turns out to linearly increase with the pre-fisc income of the capitalist.

In order to determine $y^{K}$, recall that firms use the same technology and pay the same wage in equilibrium. Hence, the profit is the same for all firms and denoted by $\pi$. Then,

$$
y^{K}=\frac{\pi F}{K} .
$$

As the production function is homogeneous of degree $\alpha$, it must be the case that

$$
\pi=(1-\alpha) A L_{f}^{\alpha}
$$

Substituting (9) into (14), and recursively into (13), (12), and (11), yields

$$
c^{U}=z+K \frac{\left(1-t_{2}\right) H w^{\frac{\alpha}{\alpha-1}}+\left(t_{2}-t_{1}\right) \bar{y}-\epsilon z}{\epsilon K+U},
$$

where $H$ is a strictly positive constant defined as

$$
H \equiv \frac{F A^{\frac{1}{1-\alpha}}\left(\alpha^{\frac{\alpha}{1-\alpha}}-\alpha^{\frac{1}{1-\alpha}}\right)}{K} .
$$

We are now in a position to determine the wage curve of the economy. Inserting (15) into (10), one obtains

$$
w=\frac{e^{1-\alpha}}{1-t_{1}}\left[z+K \frac{\left(1-t_{2}\right) H w^{\frac{\alpha}{\alpha-1}}+\left(t_{2}-t_{1}\right) \bar{y}-\epsilon z}{\epsilon K+U}\right] .
$$

This equation describes the relationship between equilibrium wage and equilibrium unemployment, as stemming from the wage setting behavior of the unions and taking the determination of the utility level of the unemployed into account.

The labor demand curve of the economy can be obtained by (9). Since all firms behave identically, we have $w_{f}=w$ and $L_{f}=(W-U) / F$. Substituting these relationships into (9) yields

$$
U=W-F\left(\frac{\alpha A}{w}\right)^{\frac{1}{1-\alpha}} .
$$


Equations (16) and (17) determine the equilibrium levels of wage and unemployment.

Proposition 3 (i) There exists a unique equilibrium level of unemployment $U^{*}>0$.

(ii) Equilibrium unemployment decreases with the degree of selfishness, $\epsilon$.

Proof: See the Appendix.

Interestingly, altruism is bad for employment in a unionized economy with philanthropy. The intuition is straightforward. If the altruistic motive is operative for the rich and they become more altruistic, charities will receive more money from them and thereupon increase their help for the poor. Thus, the utility level anticipated by workers in case of unemployment will increase. This creates an incentive for the trade unions to demand higher wages and tolerate a higher unemployment rate.

A comparison with Arrow's (1981) model is instructive. In that model, voluntary gifts to the poor are suboptimally low because the individuals do not internalize the effect of their gifts upon the other individual's welfare. This externality is the unique distortion in Arrow's model. In the current framework, a second distortion is involved, namely local monopoly unions. Individuals do not internalize the effect of their gifts upon the wage setting policy of the unions. Since more generous gifts induce a stronger wage pressure, voluntary gifts to the poor may be considered too large because they are detrimental to production efficiency.

\section{Employment effects of taxes}

The budget of the government is given by:

$$
B=t_{1} w(W-U)+\left[t_{2}\left(y^{K}-\bar{y}\right)+t_{1} \bar{y}\right] K-z U,
$$

where the three terms on the RHS respectively are the revenue from the taxation of wage income, the revenue from the taxation of profit income, and the public expenditure for 
the poor. The policy variables $\left(z, t_{1}, t_{2}\right)$ are supposed to be such that the government's budget constraint $B \geq 0$ is satisfied. We now examine the impact of each policy variable on equilibrium unemployment:

Proposition 4 Unemployment is an increasing function of $z$ and $t_{1}$ and a decreasing function of $t_{2}$.

Proof: See the Appendix.

The intuition behind the effects from $z$ and $t_{1}$ is the same as in standard models of wage bargaining. The novel insight is that unemployment is decreasing in the top marginal tax rate. An increase in the top tax rate decreases the post-fisc income of the rich without affecting the take-home wage of the employees. As a consequence, the rich decrease their donations to charities and the unemployed poor attain a lower level of consumption. This effect dampens wage pressure by the unions and increases the aggregate employment level.

The positive employment effect of the top marginal tax rate is entirely due to its impact on charitable contributions. Since the rich derive their income from pure profits, if an operative altruistic motive were absent, a marginal tax on those profits would merely transfer resources from the rich to the government, with no implications for allocative efficiency. In the current framework, taxing pure profits matters for allocative efficiency because profits are spent in a way that turns out to distort the labor allocation.

The employment effects of $t_{1}$ and $t_{2}$ can be summarized by

Corollary Tax progression is good for employment.

It is easy to see that, generally, there always exist ways of increasing progressivity, i.e. $t_{2}-t_{1}$, such that the government's budget $B$ is not worsened. A simple strategy is to keep $t_{1}$ constant and to raise $t_{2}$. Then, we have:

Proposition 5 Increasing the top marginal tax rate increases the revenue from taxation of wage income, increases the revenue from taxation of profit income, and reduces 
expenditures for the poor.

Proof: See the Appendix.

\section{Conclusion}

We have offered a simple general equilibrium model of a unionized economy where the unemployed supplement their transfers from the government with support from private philanthropy. It has been shown that a progressive income tax is good for employment and improves production efficiency. Raising the top marginal tax rate can both reduce the unemployment rate and improve the public budget. These results are driven by the following three facts: charity turns out to increase wage pressure; the rich are those who donate to charities; and, finally, the altruistic rich fail to internalize the effet of their donations on the wage setting behavior of the unions.

It is beyond the scope of this paper to examine the empirical relevance of the logical implications of the adopted assumptions. Arguably, in current unionized economies, charitable support to the poor has not much impact on the expected utility of the unem-

ployed; therefore, its effect on wage bargaining should be small. However, things may be changing. In countries like Germany, where a large fraction of the worforce is covered by collective wage agreements, recent reforms have substantially cut governmental support for the unemployed at a time where the concentration of income and wealth was on the rise. Such processes are likely to continue in the near future. In that case, the analysis containend in this paper may eventually prove to be highly relevant. 


\section{Appendix}

\section{Proof of Proposition 3}

Part (i): The equilibrium wage and unemployment are a solution to the equation system given by (16) and (17). The latter is the demand curve, which implicitly defines the wage as a strictly increasing function of the unemployment level. The wage equals the competitive wage if $U=0$ and tends to infinity if $U \rightarrow W$.

Equation (16) is the wage curve and implicitly defines the wage as a strictly decreasing function of the unemployment level. To see this, rewrite the wage curve as

$$
w\left(1-t_{1}\right)(\epsilon K+U)=e^{1-\alpha}\left\{K\left[\left(1-t_{2}\right) H w^{\frac{\alpha}{\alpha-1}}+\left(t_{2}-t_{1}\right) \bar{y}\right]+z U\right\} .
$$

Differentiation with respect to $w$ and $U$ yields

$$
\left[\left(1-t_{1}\right)(\epsilon K+U)+\frac{\alpha}{1-\alpha} e^{1-\alpha} K\left(1-t_{2}\right) H w^{\frac{1}{\alpha-1}}\right] d w=\left[z e^{1-\alpha}-w\left(1-t_{1}\right)\right] d U .
$$

The term in square bracket on the LHS is strictly positive. The term in square bracket on the RHS is strictly negative if $w\left(1-t_{1}\right)>z e^{1-\alpha}$. By (10) and (5), $w\left(1-t_{1}\right)=$ $(z+K g) e^{1-\alpha}$. Hence, the term in square bracket on the RHS is strictly negative; it follows that $d w / d U<0$.

Since the wage demanded by the union at $U=0$ is larger than the competitive wage and the wage given by the demand curve goes to infinity as $U \rightarrow W$, there exists a unique $\left(U^{*}, w^{*}\right)$, with $U^{*} \in(0, W)$, that simultaneously solves (16) and (17).

Part (ii): The degree of selfishness only affects $U^{*}$ through the wage curve. It is straightforward to verify that an increase of $\epsilon$ shifts the wage curve downwards in the space $(U, w)$. Since the demand curve is upwards sloping, increasing $\epsilon$ reduces both $U^{*}$ and $w^{*}$. Q.E.D.

\section{Proof of Proposition 4}


The policy variables $\left(z, t_{1}, t_{2}\right)$ only affect $U^{*}$ through the wage curve. Differentiating (18) with respect to $w$ and $z$ yields

$$
\left[\left(1-t_{1}\right)(\epsilon K+U)+\frac{\alpha}{1-\alpha} e^{1-\alpha} K\left(1-t_{2}\right) H w^{\frac{1}{\alpha-1}}\right] d w=e^{1-\alpha} U d z .
$$

Hence, an increase of $z$ shifts the wage curve upwards in the space $(U, w)$. Since the demand curve is upwards sloping, increasing $z$ increases $U^{*}$.

Differentiating (18) with respect to $w$ and $t_{1}$ yields

$$
\left[\left(1-t_{1}\right)(\epsilon K+U)+\frac{\alpha}{1-\alpha} e^{1-\alpha} K\left(1-t_{2}\right) H w^{\frac{1}{\alpha-1}}\right] d w=\left[w(\epsilon K+U)-e^{1-\alpha} K \bar{y}\right] d t_{1} .
$$

An increase of $t_{1}$ shifts the wage curve upwards and increases $U^{*}$ iff

$$
w(\epsilon K+U)>e^{1-\alpha} K \bar{y} .
$$

To see that (22) holds, use (10) to rewrite it as

$$
c^{U}\left(\epsilon+\frac{U}{K}\right)>\bar{y}\left(1-t_{1}\right) .
$$

By (5) and (4), the above inequality is equivalent to

$$
c^{K}+\frac{z U}{K}+U g>\bar{y}\left(1-t_{1}\right)
$$

which can be transformed using (6) and (12) into

$$
y^{K}-t_{1} \bar{y}-t_{2}\left(y^{K}-\bar{y}\right)+\frac{z U}{K}>\bar{y}-t_{1} \bar{y} .
$$

Hence, (22) holds iff

$$
\left(1-t_{2}\right)\left(y^{K}-\bar{y}\right)+\frac{z U}{K}>0
$$

which is clearly satisfied.

Differentiating (18) with respect to $w$ and $t_{2}$ yields

$$
\left[\left(1-t_{1}\right)(\epsilon K+U)+\frac{\alpha}{1-\alpha} e^{1-\alpha} K\left(1-t_{2}\right) H w^{\frac{1}{\alpha-1}}\right] d w=-\left[e^{1-\alpha} K\left(y^{K}-\bar{y}\right)\right] d t_{2} .
$$

Hence, an increase of $t_{2}$ shifts the wage curve downwards and reduces $U^{*}$. QED 


\section{Proof of Proposition 5}

By (9), revenue from taxation of wage income can be written as

$$
t_{1} w(W-U)=t_{1} F \alpha A\left(\frac{W-U}{F}\right)^{\alpha} .
$$

Since $U$ decreases with $t_{2}$, increasing the latter unambiguously increases the tax revenue.

By (13) and (14), revenue from taxation of profit income can be written as

$$
\left[t_{2}\left(y^{K}-\bar{y}\right)+t_{1} \bar{y}\right] K=t_{2}\left[\frac{F}{K}(1-\alpha) A\left(\frac{W-U}{F}\right)^{\alpha}-\bar{y}\right] K+t_{1} \bar{y} K
$$

Since $U$ decreases with $t_{2}$ and $y^{K}>\bar{y}$, increasing the top marginal tax rate unambiguously increases the tax revenue.

Finally, expenditures for the poor, $z U$, decreases with $t_{2}$ because $U$ diminishes if $t_{2}$ is increased. QED 


\section{References}

Agell, J. and P. B. Sorensen (Eds.), 2006, Tax Policy and Labor Market Performance, Cambridge: MIT Press.

Arrow, K., 1981, Optimal and voluntary income distribution, in Rosefielde, S. (Ed.), Economic Welfare and the Economics of Soviet Socialism, Cambridge: Cambridge University Press.

Atkinson, A. and T. Piketty (Eds.), 2006, Top Incomes over the Twentieth Century, Oxford: Oxford University Press.

Bach, S., Corneo, G. and V. Steiner, 2006, Top incomes and top taxes in Germany, CESifo WP. No. 1641.

Becker, I and R. Hauser, 2004, Verteilung der Einkommen 1999-2003, Report to the Ministry for Social Affairs of Germany, mimeo, University Frankfurt.

Corneo, G., 1994, Ajustement des cotisations sociales et chomage d'équilibre, Economie et Prévision 115, 107-115.

Frick, J, Goebel, J., Grabka, M., Krause, P., Schäfer, A., Tucci, I. and G. Wagner, 2005, Zur langfristigen Entwicklung von Einkommen und Armut in Deutschland, DIW Wochenbericht 72, 59-68.

Hauser, R. and B. Nolan, 1999, Changes in income poverty and deprivation over time. A comparison of eight european countries from the mid-eighties to the mid-nineties with special attention to the situation of the unemployed, Arbeitspapier Nr. 21, University Frankfurt.

Koskela, E. and J. Vilmunen, 1996, Tax progression is good for employment in popular models of trade union behaviour, Labour Economics 3, 65-80. 
Lockwood, B. and A. Manning, 1993, Wage setting and the tax system. Theory and evidence for the United Kingdom, Journal of Public Economics 52, 1-29.

Sainsbury D. and A. Morissens, 2002, Poverty in Europe in the mid-1990s: the effectiveness of means-tested benefits, Journal of European Social Policy 12, 307-327. 